\title{
Author Index Vol. 1, 1995
}

\section{Amsterdam Institute for Addiction}

Research 66 Bácskai, E. 50 Bless, R. 128 Bonnin,O. 157 Bradley, A. 152

Brink, W. van den 161,166,187,199 Brodin,M. 115 Brussel, G. van 92 Buning, E. 92

Degkwitz,P. 81 DeJong, C.AJ. 199 Facy, F. 194 Freeman, M. 128 Fuchs,WJ. 81,106 Gerada,C. 146 Gerevich, J. 50 Gossop, M. 42 Grob,PJ. 106 Hartgers,C. 166,187,208 Hartnoll,R. 3,71

Holzbach,R. 74 James, B. 76 Kalke,J. 99 Koeter, M.W.J. 187 Kokkevi,A. 194,208

Korf,DJ. 128 Köstler,A. 63 Krausz, M. 1 Kuss,H.-J. 74 Lombrail,P. 115 Mass,R. 155

Niedermeyer, U. 155 Püschel,K. 121 Raschke,P. 99 Ravndal,E. 178 Reuband, K.-H. 32,61

Rommelspacher, H. 20 Rydberg,U. 26 San,L. 64

Schulz-Schaeffer, W. J. 121 Serfaty,A. 115 Søe,D. 157 Soyka,M. 74 Staak, C.P.F. van der 199 Uchtenhagen, A. 1,68,86 Vaglum,P. 178 VanLindt,H. 12 Verheul,R. 166 Verthein,U. 99 Weiss, S. 206 Zenker,C. 139 